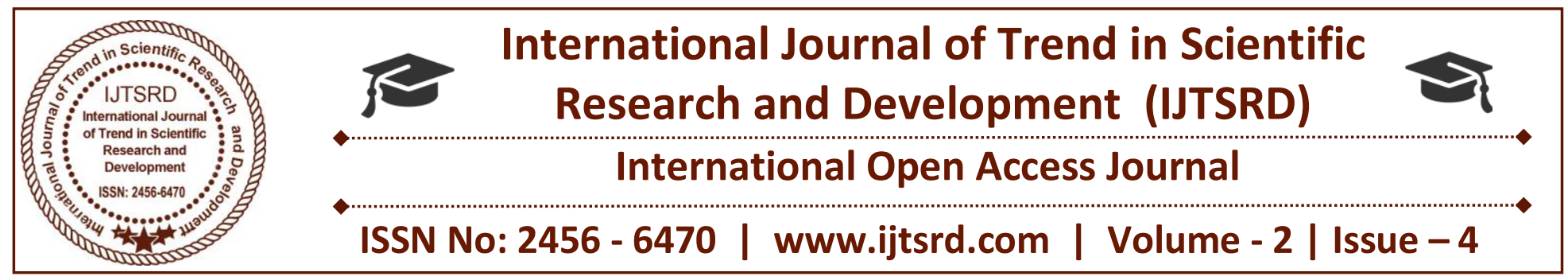

\title{
V- Drop: Automatic Book Drop
}

\author{
Swapnil Gamre ${ }^{1}$, Namrata Hande ${ }^{2}$, Ragini Mistri ${ }^{3}$, Prof. Abhishek Pandey ${ }^{4}$ \\ ${ }^{1,2,3} \mathrm{BE}$ Computer Engineering, Vidyalankar Institute of Technology, Wadala, Mumbai \\ ${ }^{4}$ GuideVIT, BE Computer Engineering, Vidyalankar Institute of Technology, Wadala, Mumbai
}

\section{EXISTING SYSTEM}

Abstract-In the existing system, Vidyalankar Institute of Technology (henceforth addressed as VIT) Library is situated on 3rd floor. Its a bit tiresome for students and professors to go upstairs for just returning books or just to extend the book return date. Efforts needed to go upstairs till 3rd floor are deduced as the proposed system gives facility to deposit those books and also reissue them on ground floor itself. Along with the fine payment, timely reminders are sent to the students/professors for reminding the return date of the book. An SMS is also sent to the librarian to empty the bins in machine.

Index Terms-VIT, Automatic Book Drop, Library, Book renewal

\section{INTRODUCTION}

Basically taking VIT Students and Staff into concern, we have put forward an effort to enhance the technology used in VIT Library System. In todays forward stepping environment, this system will prove a slight change in adopting a newer way to deposit the books issued from library. This slight change benefits VIT book readers to ease their work and also librarian will be benefited with cashless approach. Books will be dropped in such a manner that they will be sorted for the convenience of the library staff. Area below VIT Library will be used for V-DROP system.

The system will make students and staff problem of deposition of book lot easier. The efficiency of drop and go method will prove advantageous over the traditional approach being followed. Along with this, it will take care of the penalties for late return with only one account that is primarily being used. This will ensure the fine payment lot easier. The students/ professors will receive a message after the deposition of book.
The VIT library is situated on 3rd floor. The book issuing and returning is done at the same place. Each book has its barcode placed on it. This barcode is already stored in the database at the server side. The barcode on reader's ID card is scanned while issuing and an entry is made in the database. The book can be returned within the interval of 45 days. Per day fine for failing to abide by the date is Rs 5 .

Keeping the log of returned books and also the sorting of books is done by the library staff. They are also responsible for fine collection. At the time of returning, the barcode on the book is scanned to access the database and to update that the book has been returned or reissued.

\section{LIMITATION OF EXISTING SYSTEM}

Students or Professors have to go up to the 3rd floor to return the book. Fine payment is done by paying cash in the library. The current system is not competent of providing the reminders to the readers about the return dates or applicable fines.

Returning and sorting of books requires human intervention. Books cannot be returned once the library is closed.

\section{PROPOSED SYSTEM}

The system will be divided into three modules:

1. Identification of the Student and the Book records: The books will have QR codes printed on them and NFC cards attached to it on the first page. The reader will have to scan the QR code using a mobile application. After scanning the QR code, the details of the book (issue date, return date, fine if any) will be displayed on the screen. After this, he/she will place the book in the slot in the specified position so that the NFC card will be scanned properly. 
After placing the book in the slot, the reader will press a button to send the book inside for scanning of NFC card. NFC card will be used here for ensuring the security. Through NFC card, the book code on the NFC tag will be read and if it will match with the QR code on the book, then only further process will be carried out. This reduces the chance of book theft by taking it out after the verification in mobile application.

2. Actual book Drop: The actual working of the system begins after identification. Now the books unique QR code will be scanned and the program will check for any dues. If there are dues then fine will be collected through ERP system e wallet account of the reader. If the balance is insufficient, he/she has to recharge the account first and then ask for book drop.

Once the QR code is scanned and dues are paid, the reader will get an option for the reissuing of the book. If the reader intends to do so, the database will be updated and the book will be reverted back to the reader. If the reader wants to deposit the book and no dues are pending, the book will be sorted according to its category depending on the barcode group for each book and will be dropped in separate bins.

3. SMS alert: After the successful deposition of the book, the reader will get an SMS alert notifying $\mathrm{him} /$ her about the book deposition. If the penalty amount is applicable, he/she will be notified with the days for late deposition, charges for 1 day penalty and the total payment done using the primary account being used. The reader will get a SMS alert as soon as the book issued about the return date and will be given timely reminders for book returning dates. SMS alert for the librarian will also be generated whenever the bins are full, so that the person assigned can empty them.

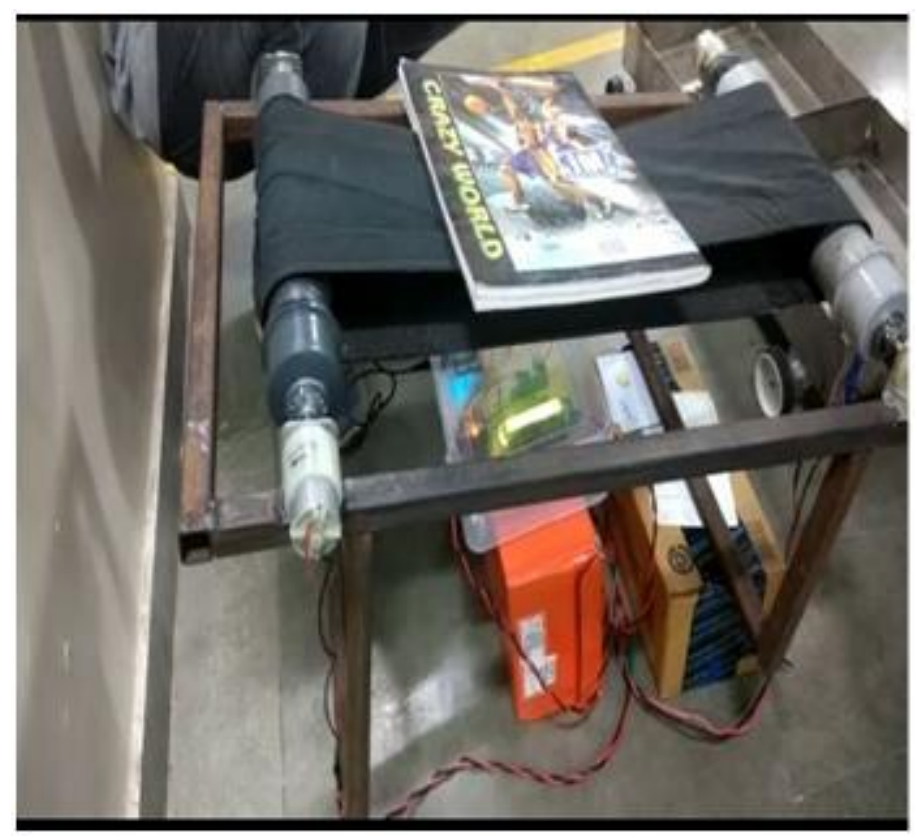

Figure 1: System in working mode

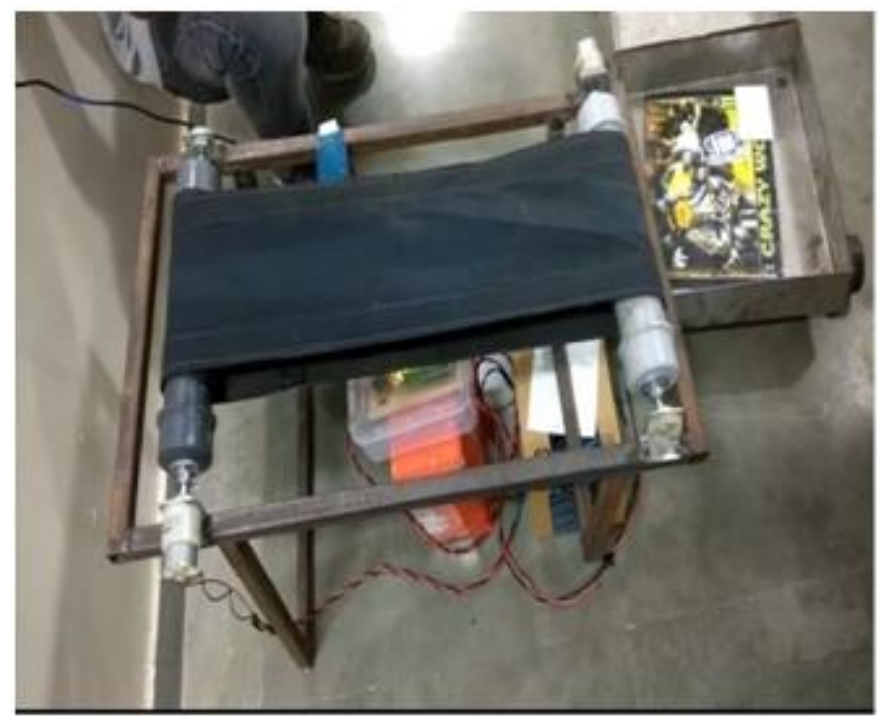

Figure 2: Book dropped in respective bin

\section{ADVANTAGES OF PROPOSED SYSTEM}

This system will have an impact on traditional way of library functioning in VIT. It will reduce the human intervention in the process along with the lesser efforts and cost. Furthermore it will have less maintenance issues and expenses. It will also help in the fine collection. The project can also be beneficiary for the cashless transactions. The following are the advantages of the system over the traditional offline system discussed in details:

1. SMS as a reminder for the last date of depositing a book: When the due date is close, reader will be informed about the last date of book to be returned through a SMS. 
2. Fine calculation: Fine will be calculated on the basis of holidays (also emergency holidays), late days.

3. Fine collection (through V-print account): Moving a step ahead towards cashless VIT, fine will be collected through V-Print account rather than dealing with cash.

4. Depositing the books in the respective bins (according to their types): Books will be sorted as Engineering and Non-Engineering books and then will be deposited in respective bin.

5. SMS to librarian whenever the Bin is full: When the bin will become full, an alert SMS will be sent to the librarian to empty the bin.

\section{CONCLUSION}

The proposed system is an automated book drop which automates the book returning and reissuing process. It also overcomes all problems of current system. It is easy to use and very efficient for readers.
As it is an unmanned system, amount of manpower will be reduced.

\section{ACKNOWLEDGMENT}

We are thankful to all those who helped us throughout the course of writing this paper. We sincerely wish to thank our project guide Prof. Abhishek Pandey, for his valuable and insightful inputs and constructive criticisms have been of utmost importance. His leadership qualities motivated us and in-depth knowledge of his field of interest was an addition in getting us prepared to work on this system.

\section{References}

[1] Boss, Richard W. AUTOMATED STORAGE/RETRIEVAL AND RETURN/ SORTING SYSTEMS. American Library Association, 2002.

[2] 3M Library. "3M Intelligent Return and Sorter System.” Online video clip. Youtube. Youtube, 26 Jan. 2012. Web. 15 April 2018. 